\title{
Impacts of polystyrene microplastics on Daphnia magna: a laboratory and a mesocosm study
}

Article

Accepted Version

Creative Commons: Attribution-Noncommercial-No Derivative Works 4.0

Al-Jaibachi, R., Laird, W. B., Stevens, F. and Callaghan, A. (2020) Impacts of polystyrene microplastics on Daphnia magna: a laboratory and a mesocosm study. Science of the Total Environment, 705. 135800. ISSN 0048-9697 doi: https://doi.org/10.1016/j.scitotenv.2019.135800 Available at https://centaur.reading.ac.uk/87683/

It is advisable to refer to the publisher's version if you intend to cite from the work. See Guidance on citing.

To link to this article DOI: http://dx.doi.org/10.1016/j.scitotenv.2019.135800

Publisher: Elsevier

All outputs in CentAUR are protected by Intellectual Property Rights law, including copyright law. Copyright and IPR is retained by the creators or other copyright holders. Terms and conditions for use of this material are defined in the End User Agreement.

www.reading.ac.uk/centaur 
Central Archive at the University of Reading

Reading's research outputs online 
1 Impacts of polystyrene microplastics on Daphnia magna: a laboratory and a mesocosm study.

2 Rana Al-Jaibachi ${ }^{1}$, William Bruce Laird ${ }^{1}$, Freya Stevens ${ }^{1}$, Amanda Callaghan ${ }^{1}$

$3{ }^{1}$ Ecology and Evolutionary Biology, School of Biological Sciences, University of Reading,

$4 \quad$ Harborne Building, Whiteknights, Reading, Berkshire, RG6 6AS, United Kingdom.

5

$6 \quad$ *Corresponding author: e-mail, a.callaghan@reading.ac.uk 


\section{Abstract}

8 Most research into microplastics (MPs) in freshwaters has concentrated on measurements

9 under controlled conditions without any link to the natural environment. Here we studied the

10 effects of a $15 \mu \mathrm{m}$ polystyrene MP on Daphnia magna survival, growth, and reproduction in

11 the laboratory. We also exposed fifteen $25 \mathrm{~L}$ freshwater mesocosms to a high concentration of

12 the same MPs. Five were controls seeded with five species found in all ponds (mosquito, water

13 flea, midge, spire shell and water mite), five identical but treated with $15 \mu \mathrm{m}$ polystyrene MPs

14 and five seeded with only mosquitoes and water fleas. The laboratory chronic toxicity test for

15 both adults and neonate Daphnia magna revealed that effects were more related to the

16 availability of food rather than the toxicity of MPs. In the mesocosms most of the MPs settled

17 in the sediment after the first week of exposure. After four weeks the D. magna population

18 decreased significantly in the MP mesocosms compared to the control mesocosms, although it

19 subsequently recovered. There was no impact on other organisms added to the mesocosms,

20 other than a difference in timing of lesser water boatman (Corixa punctata) colonisation, which

21 colonised the control mesocosms in week 4 and the treated 4 weeks later. The detrivorous,

22 sediment sifting, mayfly Leptophlebia marginata appeared in mesocosms in the fourth week

23 of sampling and with significantly higher numbers in the MP treated mesocosm. Their activity

24 had no significant impact on MPs in the water column, although numbers did increase above

25 zero. The significant decline of $D$. magna suggests that their effect in a natural situation is

26 unpredictable where environmental conditions and invertebrate communities may add

27 additional stresses. 
Plastic pollution in aquatic habitats is a serious environmental issue worldwide that has galvanised businesses, the general public and governments into taking action. Much of the early research focussed on highly visible macroplastics in marine ecosystems with fewer than $4 \%$ of research papers on freshwater (Wagner and Lambert 2018). In recent years, interest has shifted towards freshwater ecosystems and, in particular, the impact of microplastics (MPs) (Wagner et al. 2014; Eerkes-Medrano et al. 2015; Wagner and Lambert 2018). Microplastics are diverse plastics, including polyethylene and polystyrene, whose fragments are smaller than $5 \mathrm{~mm}$ in size and are produced by the degradation of larger particles or are manufactured as microbeads for use in, for example, cosmetics and toiletries (Andrady, 2011; Imhof et al., 2013; Eriksen et al., 2014). Whilst bans on the use of MPs in toiletries have been in place for a number of years, the problems remain significant since there are many pollution routes and types of MP (Rochman et al, 2019).

There is no doubt that MP pollution is widespread, with a growing body of evidence to suggest that much higher MP concentrations are found in sediments compared to the water column. In Lake Taihu (China) the average number of MPs found in the water body was $3.4-25.8$ MPs $\mathrm{L}^{-1}$, while 11- 234.6 MPs kg-1 was found in the benthic sediment (Su et al., 2016). Similarly in Lake Chiusi (Italy) an average of $0.03 \mathrm{MPs} \mathrm{L}^{-1}$ were found in the surface water whereas 234 MPs $\mathrm{kg}^{-1}$ found in the sediment (Fischer et al., 2016). Higher levels of MPs have also been measured in river sediments including sediment of the River Thames, found to contain up to $660 \mathrm{MPs} \mathrm{kg}^{-1}$ (Horton et al., 2016). It is almost certain that the organisms living in these waters are ingesting MPs. However it is premature to generalise on whether the sediment or water column will have higher numbers of MPs since the data collected, as illustrated above, use very different methodologies. 
54 Although there are numerous studies to investigate the occurrence and abundance of MPs in freshwater environments including rivers and lakes, relatively few have looked at the impact on the organisms being exposed (Sighicelli et al., 2018; Wagner and Lambert, 2018). Their size results in them being easily ingested by many aquatic organisms at various trophic levels and stages of development, including freshwater invertebrates ( Cole et al., 2013; Scherer et al., 2017; Al-Jaibachi et al., 2018a; Aljaibachi and Callaghan, 2018; Liu et al., 2019). Microplastics can be carriers of toxic chemicals e.g. polychlorinated biphenols or plasticizers added during production and bacteria that can absorb onto their surface (Talsness et al., 2009). Therefore the behaviour of MPs in a pristine state may be very different from those released into the environment.

The majority of research on the uptake and effect of MPs in freshwater organisms has been conducted in the laboratory which does not reflect the many variables found in the environment (Phuong et al., 2016; de Sá et al., 2018). Laboratory studies are nearly all undertaken on individual organisms which ignores the interactions that occur in the natural environment (Rosenkranz et al., 2009; Jemec et al., 2016). That said, these studies do give useful information on the uptake and ecotoxicity of polystyrene MPs in both laboratory and natural field conditions. Laboratory work on D. magna has shown that MPs can enter their gut system and show concentration-time dependent patterns (Nasser and Lynch, 2016; Ogonowski et al., 2016; Aljaibachi and Callaghan, 2018; Canniff and Hoang, 2018; Martins and Guilhermino, 2018). Similar results have been found in Gammarus fossarum (Blarer and Burkhardt-Holm, 2016), annelids (Lumbriculus variegatus), crustaceans (Gammarus pulex), ostracods (Notodromas monacha), mosquitoes (Culex pipiens), and gastropods (Potamopyrgus antipodarum) (Imhof et al. 2013; Al-Jaibachi, et al. 2018b). These studies are important since initial ingestion is 
more likely in lower trophic organisms which could enhance the transfer through the food chain ( Anbumani \& Kakkar 2018; Al-Jaibachi, et al. 2018a).

The relationship between laboratory results and the behaviour and interaction of MPs and invertebrates in the natural environment must be determined using more natural exposure methods. Microplastics entering a natural environment are unlikely to remain stationary but will instead be transported between environmental compartments (Lambert and Wagner, 2018). The fate and movement of MPs will depend on hydrology and vegetation (Lambert and Wagner, 2018) and in lakes is likely to depend on sediment disturbance. The abundance of MPs in most freshwater environments investigated highlights questions about their impact on the biota biodiversity, food chain, community composition and predator-prey interactions and the possibility to accumulate in the food chain or transfer ontogenically to different environments (Wright et al., 2013; Al-Jaibachi et al., 2018a; Cuthbert et al., 2019).

Here we investigated the chronic ecotoxicological impact of PS MPs size $15 \mu \mathrm{m}$ in laboratory condition on adults and neonate Daphnia magna before taken it out into the field to study the abundance and impact on a community of freshwater invertebrates. Daphnia magna is a standard ecotoxicity model and shows a high sensitivity to toxicants (Pablos et al., 2015). They are also used as models of filter feeders in the freshwater environment and have been utilised to examine the uptake and depuration of MP sizes from $1 \mathrm{~nm}$ to $2 \mu \mathrm{m}$ (Besseling, Wang, $\mathrm{Lu}$, et al. 2014; Aljaibachi and Callaghan 2018). Work has also been directed to life-history effects and both the acute and chronic toxicity of MPs on D. magna (Ogonowski et al., 2016; Aljaibachi and Callaghan, 2018; Martins and Guilhermino, 2018).

Freshwater mesocosms are widely recognised as supporting greater regional invertebrate diversity than most other freshwater ecosystems in the UK and across Europe and can be rapidly colonised by variety of organism ( Krebs and Davies, 2009; Céréghino et al., 2010). 
103 The small mesocosms chosen to implement the experiment have been studied previously and

104 have demonstrated their value in rapidly measuring the impact of environmental stressors on

105 freshwater communities in a controlled but natural environment (Céréghino et al., 2008).

106 Fluorescent $15 \mu \mathrm{m}$ PS MPs were chosen for studies into the ecotoxicological effect on Daphnia

107 magna because of concerns regarding our ability to detect smaller MPs in the mesocosms. The

108 impact of MPs on the population size and community were examined by manipulating the

109 mesocosms so that at the start of the study had the same population size and composition. The

110 animals used were all taken from the mesocosms where they had naturally colonised. They

111 included C. pipiens and D. magna as well as predators and animals that dwell in the sediment.

112 The mesocosms were monitored for 12 weeks. We hypothesized that MPs would sink to the

113 sediment and be unavailable to animals in the water column with a consequent lack of effect

114 on population size or community composition. 


\subsection{Preparation of microplastics (MPs)}

117 Fluorescent $15 \mu \mathrm{m} \quad$ green carboxylate-modified polystyrene MPs (density

$1181.06 \mathrm{~g} \mathrm{~cm}^{-3}$, excitation $470 \mathrm{~nm}$; emission $505 \mathrm{~nm}$, Sigma-Aldrich, UK) were used in all 119 experiments. Microplastics were stored as a stock suspension (1\%) and mixed as per Aljaibachi 120 et al. (2018a). The number of PS particles from the stock solution were counted under the epi121 fluorescent microscope at 10x magnification (Carl Zeiss Axioskop, Wetzlar, Germany). Each one 122 milliliter of stock solution contained $5 \times 10^{6}$, MPs $\mathrm{mL}^{-1}$. 2.2. Daphnia cultures

123 Daphnia magna were obtained from the Water Research Centre (WRC, Medmenham, UK)

124 and cultured at the University of Reading for more than ten years prior to this experiment.

125 Full details of culturing methods are given in (Hooper et al., 2006). Daphnia were maintained

126 in Organization for Economic Co-operation and Development (OECD) reconstituted water

127 (media) and fed yeast and C. vulgaris var Viridis following the methods of (Hayashi et al.,

128 2008). New cultures of Daphnia were prepared with 15 neonates in 1,200 $\mathrm{ml}$ beakers filled

129 with OECD media (the progeny of these neonates are the first brood). Juveniles were

130 removed regularly from the culture and the media was changed once a week. The third brood

131 produced by the original 15 neonates were used for experiments.

\subsection{Uptake of microplastics with and without algae}

134 Individual 18 day old D. magna were placed in $50 \mathrm{ml}$ beakers filled with media and starved for $24 \mathrm{~h}$ prior to exposure. In a random design, animals were exposed to one of 4 concentrations of MP (2, 4, 8 and $\left.16 \times 10^{5} \mathrm{ml}^{-1}\right)$ with varying amounts of algae (Table 1) for $60 \mathrm{~min}$. Each treatment was replicated three times. Animals were rinsed in distilled water to remove any MPs adhering to the outside and frozen at $-20^{\circ} \mathrm{C}$. Individual animals were homogenized using a glass 
140 Eppendorf tube. A further $500 \mu$ distilled water was pipetted over to rinse the pestle. The

141 homogenate was mixed using a whirlimixer and $500 \mu \mathrm{l}$ removed and placed onto a nucleopore

142 track-etched membrane (Whatman, UK) $10 \mu \mathrm{m}$ with a white background. A manual air pump

143 was used to filter the homogenate. The membrane was examined under an epi-fluorescent

144 microscope (Zeiss Axioskop) at a magnification of 10x to count the MPs.

\section{$145 \quad 2.3$ Adult Chronic Toxicity Tests}

146 Third brood D. magna adults (18 days old) were placed individually into glass beakers filled

147 with $50 \mathrm{~mL}$ of OECD reconstituted water (media) and exposed to one of six treatments ranging

148 from only algae or only MPs and combinations of the two (Table 1), each with five replicates.

149 Media and concentrations of MPs were renewed three times per week. In all treatments, life

150 history characteristics (survival and reproduction) were monitored for 21 days. Neonates were

151 counted daily and removed. Animals unable to swim after gentle stirring for $15 \mathrm{~s}$ were counted

152 as dead. The experiment was run at $20 \pm 2{ }^{\circ} \mathrm{C}$, light:dark 16:8 h.

\subsection{Neonate Chronic Toxicity Test}

154 A standard chronic toxicity test was conducted with reference to OECD guideline 211, with 155 the exception that five individuals were used (OECD, 2012). Five individuals from third-brood 156 neonates $(<24 \mathrm{~h})$ were placed in $50 \mathrm{~mL}$ glass beakers and exposed to MPs and/or green algae

157 Chlorella vulgaris (Table 2). Media and concentrations were renewed three times a week and 158 life history characteristics (survival, reproduction and growth) were monitored daily for 21 159 days. Body length (from the top of the head to the base of the tail spine) was measured every 160 other day under a stereomicroscope. The experiment was run at $20 \pm 2{ }^{\circ} \mathrm{C}$, light : dark 16:8 $\mathrm{h}$.

\section{2.4. Study site and mesocosms}

162 Thirty two mesocosms had previously been dug in the experimental grounds at the University 163 of Reading, Berkshire, England $\left(51^{\circ} 26^{\prime} 12.2^{\prime \prime} \mathrm{N}, 0^{\circ} 56^{\prime} 31.2^{\prime \prime} \mathrm{W}\right)$ in 2012 . The mesocosms were 
164 laid out in a Latin square, with three metre intervals in three rows of eight mesocosms. Each mesocosm was a sunked bucket of diameter $48 \mathrm{~cm}$ depth $30 \mathrm{~cm}$ lined with a rubber pond liner.

166 Fifteen of these mesocosms were randomly selected for use in this study.

167 The mesocosms had been naturally colonised by macroinvertebrates over the previous five

168 years. These were all removed including the sediments by passing the mesocosm water through 169 a sieve (dimensions $6 \times 12 \mathrm{~cm} ; 250 \mu \mathrm{m}$ pore size) and placing contents onto a white plastic sampling tray $(25 \times 35 \times 5 \mathrm{~cm})$ with some water.

\subsubsection{Preparation and sampling of the mesocosms community}

172 Ten of the 15 mesocosms were randomly selected for this experiment. Previous analysis of 173 abundances during a pilot state determined that five species could be reintroduced in the same numbers into each mesocosm, in numbers that reflected the natural populations at the time (species and numbers in Table 2). Each mesocosm was filled with $25 \mathrm{~L}$ of rain water then the

176 level marked to allow refilling each week to maintain the water level. Five randomly selected 177 mesocosms were left untreated as a control. Another five were treated with $500 \mu 1$ of the original washed MP stock $\left(5,000,000 \mathrm{MPs} \mathrm{mL}^{-1}\right)$ as a final concentration of $100 \mathrm{MPs} \mathrm{mL}^{-1}$. The mesocosms were then left for one week to allow for any disturbance and stress to organisms caused by setting up the experiment.

182 Weekly sampling then followed using a standardised technique; using a mesocosm net of approx. $60 \mathrm{~mm} \times 120 \mathrm{~mm}$, with a small enough mesh size to collect both the zooplankton such as D. magna and other invertebrates such as mosquito larvae (Culex spp.). The net was swept through the water using a figure of 8 motion four times $10-15 \mathrm{~cm}$ below the surface of the water. Samples were then placed in a 1 litre plastic bottle and removed to identify 
macroinvertebrates in the laboratory using a stereo microscope and number of keys (Croft, 1986; Greenhalgh and Ovenden, 2007; Dobson et al, 2013). Identified organisms were counted and then returned to the mesocosm from which they came. All members of each species were

190 individually counted, except for D. magna, numbers of which were estimated by counting the 191 number of individuals in $1 \mathrm{~mL}$, and then multiplying this by the number of $\mathrm{mL}$ in the sample

192 due to the very high numbers of individuals. This process was repeated once per week over 12 weeks, with the initial set up on and addition of the MPs on the $12^{\text {th }}$ June 2017 , first data collection on the $19^{\text {th }}$ June 2017 , and the final samples taken on the $29^{\text {th }}$ August 2017. Samples were taken between $10 \mathrm{am}$ and $12 \mathrm{pm}$ weekly.

\subsubsection{Distribution of microplastics in mesocosms}

197 Five of the 15 mesocosms not used in section 2.4.1 were treated as before but to each was added $2 \mathrm{~kg}$ of soil from the area around the mesocosms along with $25 \mathrm{~L}$ of rain water. These were set up to specifically measure the distribution of the MPs in the pond over time, not the animals. Nevertheless approximately equal numbers of $D$. magna and Culex larvae were added to the mesocosms since they were the dominant organisms in the mesocosms. The mesocosms were then treated with $500 \mu 1$ of stock MP solution as detailed in section 2.4.1. The mesocosms were re-filled with rain water to $25 \mathrm{~L}$ weekly after samples were taken.

The mesocosms were left undisturbed for a week, then samples were taken weekly from the $22^{\text {nd }}$ June 2017 until the $10^{\text {th }}$ August 2017. Five $1 \mathrm{~mL}$ water samples were taken from each of two depths ( $5 \mathrm{~cm}$ under water surface and $5 \mathrm{~cm}$ above sediment), using a $1 \mathrm{~mL}$ and then water samples were mixed together before being filtered onto a nucleopore track-etched membrane (Whatman, Kent, UK) $<10 \mu \mathrm{m}$, by using a glass vacuum filter holder connected to a manual 210 air pump. 
211 Approximately $5 \mathrm{~g}$ of sediment was collected using a spatula and stored in a $5 \mathrm{~mL}$ plastic tube.

212 Half of this sediment was spread directly onto a glass microscope slide to count the MPs under

213 an epi-fluorescent microscope.

214 2.5. Statistical analysis

215 Generalized linear model (GLM) and post hoc Tukey's comparisons of laboratory life history

216 data were undertaken using SPSS 21 (SPSS, 2012),. Growth rate data were analysed using

217 UNIANOVA (mixed model), followed by post-hoc pairwise comparisons (growth rate $\times$

218 treatments $\times$ time).

219 Probit analysis was conducted for the chronic toxicity tests (mortality rate for adults and

220 neonates) and response curves for different concentrations were produced as a scatter plot using

221 (Minitab V. 17).

222 The abundance of MPs in the mesocosms were analysed using (GLM). Analysis assumed a quasi-Poisson error distribution as counts were found to be over dispersed compared to degrees 224 of freedom.

225 The weekly abundance of invertebrate groups was analysed in R v3.4.2 (R Development Core 226 Team, 2017). Generalized Linear Model (GLM) was used assuming a quasi-Poisson error

227 distribution since they were not normally distributed, as assessed by Shapiro-Wilk's test ( $\mathrm{p}<$ $2280.05)$.

229 Rainfall and air temperature data were obtained from the University of Reading Atmospheric

230 Observatory and analysed by correlation analysis package in R v3.4.2 against MPs number in 231 the mesocosm water column. 


\section{Results}

233

234

235

236

237

238

239

240

241

242

243

244

245

246

247

248

249

250

251

252

253

254

255

256

\subsection{Uptake of increasing concentrations of MPs}

Ingestion of MPs by D. magna without algae increased significantly as MP concentration increased $\left(\mathrm{F}_{3,32}=14.12, p<0.001\right.$, Fig $\left.\mathrm{S} 1\right)$. The same was true wherever MPs $>$ algae $(\mathrm{F}$ $3,32=29.20, p<0.001)$. When $D$. magna were exposed to equal amounts of MP and algae $(\mathrm{MP}=\mathrm{algae})$, there was no increase in ingestion with increasing concentration $\left(\mathrm{F}_{3,32}=0.415\right.$, $p=0.743$ ). The mean number of MPs ingested by $D$. magna exposed to algae $>$ MPs significantly decreased as algal concentration increased $\left(\mathrm{F}_{3,32}=148.63, p<0.001\right)$.

\subsection{Adult Chronic toxicity test}

Low availability of algae significantly increased adult mortality $\left(\mathrm{X}^{2}(5, \mathrm{n}=30)=17.4, p=0.004\right)$ (Fig. 1). The presence of MPs had no impact, positively or negatively on survival, either with low $(U=10, p=0.317)$ or high algal concentrations $(U=10, p=0.513)$.

\subsection{Reproduction Test}

A 21-day reproduction test of adult D. magna revealed significant differences in the mean number of offspring between treatments $\left(\mathrm{X}^{2}(5, \mathrm{n}=30)=216.1, p=0.001\right)$ (Fig. 2). This was because treatments with low food were associated with low numbers of offspring (S1 Table $1)$.

\subsection{Neonate chronic toxicity test}

Mortality tests were significantly different between treatments exposed to low and high algae concentrations, irrespective of the presence of MPs $\left(X^{2}(5, n=30)=17.79, p=0.003\right)$ (Fig. 3).

\subsection{Reproduction test following neonate exposure to MPs}

A 21-day reproduction test of adult D. magna revealed significant differences in the mean number of offspring between treatments $\left(X^{2}(5, n=30)=1032, p>0.001\right.$, Fig. 4). This was 
because low amounts of algae were associated with a reduction in reproduction: MPs had no impact (S1 Table 2).

259

\subsection{Growth Rate}

261 There were highly significant differences in growth rate between the treatments $\left(F_{45,283}=3.455\right.$, $262 p<0.001$ ) (Fig. 5). Growth rate was higher in treatments with high levels of algal food (S1 263 Table 3).

\subsection{Distribution of microplastics between the water and sediment in mesocosms}

265 Significantly more MPs were measured in sediment compared to water over time $\left(\mathrm{F}_{(2,68)}=59.4\right.$, p <0.001) (Fig. 6). The number of MPs in the water body remained constant over time, with no evidence of a change in number $\left(\mathrm{F}_{(1,33)}=0.33, p=0.567\right)$ (Fig. 6). The abundance of MPs in the water column showed no correlation with increase in air temperature, correlation $=-0.06$; $F_{(1,5)}=0.018, p=0.898$ and a non-significant negative with rainfall correlation of $=-0.70$;

$270 \quad \mathrm{~F}_{(1,5)}=0.1361, p=0.727$.

\subsection{Effects of microplastics on species abundance}

Daphnia magna numbers fluctuated between weeks but overall there were no significant

274 differences between controls and mesocosms exposed to MPs at the end of 12 weeks (Fig. 7) ( $Z=0.918, p=0.36)$. However, on a week by week basis, there were some highly significant differences, with lower D. magna numbers in the MP treated mesocosms in the first half of the experiment (SI Table 4).

278 Similarly overall abundances of other macroinvertebrates showed no effect of treatment over

279 the 12 weeks $(C$. pipiens $Z=-1.055, p=0.29 ; P$. antipodarum $Z=1.596 ; P=0.110$;

280 Hydrachnidia $Z=0.005 ; P=0.996 ; C$. plumbeus $Z=-1.168, P=0.24)$. Abundances of 
macroinvertebrates that had independently colonised the mesocosms suggested an impact on only one species, the mayfly Leptophlebia spp. which started to appear from the fourth week of sampling and was significantly dominant in mesocosms treated with MPs $\mathrm{X}^{2}(1)=5.62, p$

$284=0.018$ (Fig. 8 A). Corixa punctata $($ Lesser water boatman), which also appeared in the

285 fourth week of sampling in the control mesocosm was not affected by MP treatment $\mathrm{X}^{2}(1)=$

$2860.683, p=0.40$ ) (Fig. 8 B). Despite the lack of overall significant differences, there were

287 clearly significant differences between treatments in various mesocosms in certain weeks

288 (Tables SI 5-7).

\section{4. Discussion}

290 Microplastic pollution in freshwater environments is a global challenge to ecosystem and 291 human health, and the long-term effect are still poorly understood (Horton et al., 2017; 292 Rochman et al., 2019). Most studies have focused on laboratory experiments to examine the 293 uptake and toxicity of MPs in freshwater invertebrates with limited results from fields studies

294 (Wagner and Lambert, 2018). Here, for the first time we examine the abundance and chronic ecotoxicological effects of $15 \mu \mathrm{m}$ polystyrene MPs on freshwater organisms in the laboratory

296 and in small mesocosms.

297 Laboratory chronic toxicity tests with $D$. magna adults and neonates exposed to two $15 \mu \mathrm{m}$ 298 polystyrene MP concentrations (100 and $800 \mathrm{MPs} / \mathrm{mL}$ ) revealed that mortality was linked to 299 algal food availability, not exposure to MPs, despite MP ingestion. This suggests some 300 selectivity in eating algae over MPs, something that has been demonstrated previously.

301 Daphnia exposed to primary MPs or kaolin, with low and high food concentrations, revealed 302 life history trait changes solely linked to food concentration, not MPs (Ogonowski et al., 2016). 
303 Our previous research using $2 \mu \mathrm{m}$ polystyrene MPs was designed to look specifically at the

304 impact of food, using MPs of approximately the same size of the algal cell with algal 305 concentrations chosen based on the minimum and maximum normal daily feeding of Daphnia 306 (Aljaibachi and Callaghan, 2018). When exposed to a single concentration of $2 \mu \mathrm{m}$ MPs

307 Daphnia almost immediately ate them in large quantities in proportion to their concentration, 308 a finding replicating that of Pavlaki et al., (2014). However we found that Daphnia given algae 309 with MPs were quite selective, preferentially eating algae over $2 \mu \mathrm{m}$ MPs (Aljaibachi and 310 Callaghan, 2018), a result found elsewhere with Daphnia selectively feeding on phytoplankton 311 rather than clay particles (DeMott, 1986).

312 A number of studies have shown that MPs fed to laboratory organisms have practically no 313 impact in the confines of the systems used (Schür et al., 2019; Wang et al., 2019). Reproduction tests for adults and neonates showed a similar effect in that food availability had an impact, but MPs did not. A similar result was found with Daphnia exposed to primary MPs or kaolin, with

316 low and high food concentrations, where Daphnia life history trait differences were linked to

317 food concentration, not MPs (Ogonowski et al., 2016).

318 Given that the MPs used were pristine and had not been in contact with any toxins which might 319 adhere to their surface, we can say with confidence that, in themselves, these particles have no important effect on laboratory Daphnia. It could simply be the case that they are too large to

321 be ingested by neonates, but the experiments here took neonates through to adults, with no 322 effect and animals definitely ingested MPs.

323 Studies on different types of MPs and smaller sizes of MP have found toxic effects. Deposit324 feeding marine lugworms, Arenicola marinara, fed on plasticised polyvinylchloride under laboratory conditions at concentrations found in the environment suffered depleted energy reserves which were probably linked to a reduction in feeding and an inflammatory response 
327 (Wright et al., 2012). Likewise, marine mussels Mytilus edulis fed factory clean high-density polyethylene up to $80 \mu \mathrm{m}$ in size displayed toxic effects including a strong inflammatory response and was related to cellular uptake (von Moos et al 2012). One explanation for the lack of effect in our research is that the polystyrene is less toxic than other MPs (Wright et al., 2012; von Moos et al., 2012). A study on $20 \mu \mathrm{m}$ polystyrene MPs in the marine copepod Calanus hegolandicus also found no effect on egg production or survival (Cole et al 2015). Looking at these and other studies, a theme has emerged in that different plastics and MP sizes are being used in different studies, generating conflicting results. MPs cannot be treated as though they are one type of stressor and conclusions based on simple experiments and approaches are probably not informative. There is an argument for a systematic analysis of MP size, type, concentration, test organism and exposure method (de Sa et al 2018). . We would also argue that studies of effects should not be confined to laboratory systems. Laboratory experiments have little relation to natural systems where external factors can play a role in the disturbance and abundance of MPs, including the presence of competitors, predators and temperature and rainfall.

342 The mesocosm experiment was conducted during a year with an extremely hot and dry summer and evaporation of water from the mesocosms was an issue; water had to be added to maintain

344 the volume. This was an issue in both control and treated mesocoms and there was no evidence 345 that this mixed the MPs up into the water column. Temperature and rainfall were also not 346 significantly correlated with MP numbers in the water column. After the second week of the 347 experiment MPs fell to the bottom of the mesocosms, leaving almost none in the water column.

348 This has also been shown in larger, more natural systems such as lakes (Su et al., 2016). the controls for the first seven weeks of exposure. Although MPs fell to the sediment after two 
weeks, Daphnia would have been exposed to high levels of MPs initially. Any negative impact would be evident in the first few weeks but disappear in a new generation (after 21 days) as the MPs effectively disappeared. This is in line with transgenerational research where $D$. magna exposed to pristine microspheres (mixed sizes of $1-5 \mu \mathrm{m}$ ) recovered if they were placed into clean water, although they suffered effects on mortality, reproduction and the population growth rate up to third generations post exposure (Martins and Guilhermino, 2018).

The population abundance of other species in the mesocosms was variable. The mosquito $C$. pipiens fluctuated in number over 12 weeks in both control and treated mesocosms but it is well known that mosquito populations are very variable and seasonal (Ortiz-Perea et al., 2018; Townroe and Callaghan, 2015). Culex pipiens was not significantly affected by the presence of MPs which agrees with research on Culex mosquitoes showing that 15 MPs had no effect on mortality or growth rate (Al-Jaibachi et al, 2018).

Although not added at the start of the experiment, the mayfly Leptophlebia spp rapidly colonised the mesocosms with significantly more in MP-treated mesocosms. Since Leptophlebia species are detritivores (Sweeney et al, 1986), there would have been more food availability in treated ponds from D. magna deaths in the first 6 weeks. This may have resulted in more individuals surviving and being collected during sampling. A second species to colonise ponds was the lesser water boatman, Corixa punctata. This is a potential competitor for food since it has a diet of algal cells but there was no significant difference in numbers between mesocosm treatments.

373 The abundance of MPs in most freshwater environments investigated highlights questions 374 about their impact on the biota biodiversity, food chain, community composition and predatorprey interactions and the possibility to accumulate in the food chain or transfer ontogenically 
to different environments. Trophic transfer via predation has been identified as a potentially major pathway through which MPs can move through food webs (Batel et al., 2016; Chae and An, 2017; Nelms et al., 2018; Provencher et al., 2018), however quantifications of how exposure to MP pollution influences trophic interaction strengths are lacking, especially in highly vulnerable, understudied freshwater environments (Blettler et al., 2018). aibachi, et al. 2018a; Al-Jaibachi, et al. 2018b; Rillig 2012; Wright et al. 2013) we demonstrate that MPs can be transferred and retained trophically from filter feeding organisms to higher predators, and that trophic transference relates to consumption rates. Predation by larval $C$. flavicans towards larval mosquito prey was significant irrespective of prior prey exposure to MPs. Neither search efficiency (attack rate) nor time taken to subdue, capture and digest prey (handling time) was significantly affected by prey MP exposure. Whilst both the area of attack rate and handling time parameters have been shown to be heavily context-dependent e.g. (Barrios-O’Neill et al., 2016; Cuthbert et al., 2018b), here we show that the presence of MP pollution does not elicit changes to predation rates. Therefore, MPs are likely to be readily transferred to predators from prey in MP-polluted systems.

To conclude, this research addresses a key knowledge gap, namely that little is known about the ecological impacts of MPs in the freshwater natural environment. Most research to date has focused on laboratory studies which don't take biotic and abiotic environmental changes into account. Daphnia numbers were significantly reduced in MP treated mesocosms despite no effect on other organisms, other than an increase in de novo colonisation, and no effect on

397 Daphnia life history parameters in the laboratory. The effects of $15 \mu \mathrm{m}$ polystyrene MPs on Daphnia magna survival, growth, and reproduction in the laboratory were similar to a parallel study of ours using $2 \mu \mathrm{m}$ polystyrene MPs. This showed that the availability of algal food was 400 far more important than any toxic impact of the MPs. This demonstrates that laboratory studies 
401 can indicate effects only under the conditions set. Most of the MPs had settled in the mesocosm 402 sediment after the first week of exposure which was not possible in the laboratory since no 403 sediment was used. The study highlights a need to look at the availability of both food and 404 MPs in natural environments where a community of organisms are interacting. 
406 Figure legends

407

408 Figure 1 Mortality of Daphnia magna for 21 days, expressed as a function of time, after chronic

409 MP exposure in the laboratory under high and low food conditions.

410 Figure 2 Effects of combinations of high and low MPs and algae concentrations on the mean

411 number of offspring of Daphnia magna. Error bars indicate $\pm 95 \%$ confidence intervals.

412 Results obtained under laboratory conditions.

413 Figure 3 Mortality rate over 21 days for neonate Daphnia magna after exposure to different

414 treatments of MPs and algae, under laboratory conditions.

415 Figure 4 Daphnia magna reproduction (neonate production) after 21 days exposure to a range 416 of MP and algae treatments (algae (Low), algae (High), Algae = MP (Low), Algae = MP(High), 417 Algae $>$ MP, MP>Algae). Error bars indicate $\pm 95 \%$ confidence. Results obtained under 418 laboratory conditions.

419 Figure 5 Effect of 21 days exposure to different combinations of MPs and algae (Algae (Low), 420 Algae (High), Algae $=$ MP(Low), Algae $=$ MP(High $),$ Algae $>$ MP, MP $>$ Algae $)$ on the body 421 length of Daphnia magna. Each point represents the mean of five replicates \pm standard error 422 (SE). Results obtained under laboratory conditions.

423 Figure 6 The mean number of MPs in the mesocosm sediment and water body \pm SE. In the 424 mesocosms.

425 Figure 7 Mean abundance of Daphnia magna in the mesocosms over the experimental period 426 in relation to treatments. The error bars indicate the standard error $(\underline{\underline{S}} \mathrm{SE})$ of the mean. 
427 Figure 8 The mean abundance of (A) Leptophlebia spp. (mayfly larvae) and (B) Corixa 428 punctate (lesser water boatman) in the mesocosms over the experimental period in relation to 429 treatments. The error bars indicate the standard error $\pm \mathrm{SE}$ of the mean. 
431 Ethics committee approval was not required.

\section{Data accessibility}

433 Data files are available in online supplementary material.

\section{Author contribution}

435 All authors provided substantial contributions to conception and design, or acquisition of data, or analysis and interpretation of data; were involved in drafting the article or revising it critically for important intellectual content; approved the final version to be published; and agree to be accountable for all aspects of the work in ensuring that questions related to the accuracy or integrity of any part of the work are appropriately investigated and resolved.

\section{Competing interests}

441 We declare we have no competing interests.

\section{$442 \quad$ Funding}

443 This research did not receive any specific grant from funding agencies in the public, 444 commercial, or not-for-profit sectors.

\section{References}

Al-Jaibachi, R., Cuthbert, R.N., Callaghan, A., 2018a. Examining effects of ontogenic microplastic transference on Culex mosquito mortality and adult weight. Sci. Total Environ. 651, 871-876. https://doi.org/10.1016/j.scitotenv.2018.09.236

Al-Jaibachi, R., Cuthbert, R.N., Callaghan, A., 2018b. Up and away: ontogenic transference as a pathway for aerial dispersal of microplastics. Biol. Lett. 14. mortality and reproduction in relation to food availability. PeerJ 6, e4601. 
Anbumani, S., Kakkar, P., 2018. Ecotoxicological effects of microplastics on biota: a review. Environ. Sci. Pollut. Res. 25, 14373-14396. https://doi.org/10.1007/s11356-018-1999-x

Andrady, A.L., 2011. Microplastics in the marine environment. Mar. Pollut. Bull. 62, 1596605. https://doi.org/10.1016/j.marpolbul.2011.05.030

Besseling, E., Wang, B., Lu, M., Koelmans, A.A., 2014a. Nanoplastic A ff ects Growth of S. obliquus and Reproduction of D. magna. Environ. Sci. Technol. 48, 12336-12343.

Besseling, E., Wang, B., Lürling, M., Koelmans, A. a, 2014b. Nanoplastic Affects Growth of S. obliquus and Reproduction of D. magna. Environ. Sci. Technol. 48, 12336-12343. https://doi.org/10.1021/es503001d

Blarer, P., Burkhardt-Holm, P., 2016. Microplastics affect assimilation efficiency in the freshwater amphipod Gammarus fossarum. Environ. Sci. Pollut. Res. 23, 23522-23532. https://doi.org/10.1007/s11356-016-7584-2

Canniff, P.M., Hoang, T.C., 2018. Microplastic ingestion by Daphnia magna and its enhancement on algal growth. Sci. Total Environ. 633, 500-507. https://doi.org/10.1016/j.scitotenv.2018.03.176

Céréghino, R., Biggs, J., Oertli, B., Declerck, S., 2008. The ecology of European ponds: Defining the characteristics of a neglected freshwater habitat. Hydrobiologia 597, 1-6. https://doi.org/10.1007/s10750-007-9225-8

Céréghino, R, Ruggiero, A., Marty, P., Angélibert, S., 2010. Biodiversity and distribution patterns of freshwater invertebrates in farm ponds of a south-western French agricultural landscape, in: Oertli, B., Céréghino, Régis, Biggs, J., Declerck, S., Hull, A., Miracle, M.R. (Eds.), Pond Conservation in Europe. Springer Netherlands, Dordrecht, pp. 43-51. https://doi.org/10.1007/978-90-481-9088-1_5 
2013. Microplastic ingestion by zooplankton. Environ. Sci. Technol. 47, 6646-6655. https://doi.org/10.1021/es400663f

Cole, M., Lindeque, P., Halsband, C., Galloway, T.S., 2011. Microplastics as contaminants in the marine environment: a review. Mar. Pollut. Bull. 62, 2588-2597.

Cuthbert, R.N., Al-Jaibachi, R., Dalu, T., Dick, J.T.A., Callaghan, A., 2019. The influence of microplastics on trophic interaction strengths and oviposition preferences of dipterans. Sci. Total Environ. 651, 2420-2423. https://doi.org/10.1016/j.scitotenv.2018.10.108

de Sá, L.C., Oliveira, M., Ribeiro, F., Rocha, T.L., Futter, M.N., 2018. Studies of the effects of microplastics on aquatic organisms: What do we know and where should we focus our efforts in the future? Sci. Total Environ. 645, 1029-1039.

Eerkes-Medrano, D., Thompson, R.C., Aldridge, D.C., 2015. Microplastics in freshwater systems: A review of the emerging threats, identification of knowledge gaps and prioritisation of research needs. Water Res. 75, 63-82. https://doi.org/10.1016/j.watres.2015.02.012

Eriksen, M., Lebreton, L.C.M., Carson, H.S., Thiel, M., Moore, C.J., Borerro, J.C., Galgani, F., Ryan, P.G., Reisser, J., 2014. Plastic Pollution in the World's Oceans: More than 5

Fischer, E.K., Paglialonga, L., Czech, E., Tamminga, M., 2016. Microplastic pollution in lakes and lake shoreline sediments - A case study on Lake Bolsena and Lake Chiusi (central Italy). Environ. Pollut. 213, 648-657. https://doi.org/10.1016/j.envpol.2016.03.012

504 Hartmann, N.B., Hüffer, T., Thompson, R.C., Hassellöv, M., Verschoor, A., Daugaard, A.E., 

Lusher, A.L., Wagner, M., 2019. Are We Speaking the Same Language? Recommendations for a Definition and Categorization Framework for Plastic Debris. Environ. Sci. Technol. 53, 1039-1047. https://doi.org/10.1021/acs.est.8b05297

Horton, A.A., Svendsen, C., Williams, R.J., Spurgeon, D.J., Lahive, E., 2016. Large microplastic particles in sediments of tributaries of the River Thames, UK - Abundance, sources and methods for effective quantification. Mar. Pollut. Bull. 114, 218-226. https://doi.org/10.1016/j.marpolbul.2016.09.004

Horton, A.A., Walton, A., Spurgeon, D.J., Lahive, E., Svendsen, C., 2017. Microplastics in freshwater and terrestrial environments: Evaluating the current understanding to identify the knowledge gaps and future research priorities. Sci. Total Environ. 586, 127-141.

Imhof, H.K., Ivleva, N.P., Schmid, J., Niessner, R., Laforsch, C., 2013. Contamination of beach sediments of a subalpine lake with microplastic particles. Curr. Biol. 23, R867-8.

Jemec, A., Horvat, P., Kunej, U., Bele, M., Kržan, A., 2016. Uptake and effects of microplastic textile fibers on freshwater crustacean Daphnia magna. Environ. Pollut. 219, 201-209. https://doi.org/10.1016/j.envpol.2016.10.037

Krebs, J.R., Davies, N.B., 2009. Behavioural ecology: an evolutionary approach. John Wiley \& Sons.

Lambert, S., Wagner, M., 2018. Microplastics Are Contaminants of Emerging Concern in Freshwater Environments: An Overview Scott, in: Lambert, S., Wagner, M. (Eds.), Freshwater Microplastics. Springer, Cham, pp. 1-23. https://doi.org/10.1007/978-3-319- 
exposure induces immobilization, reproduction, and stress defense in the freshwater cladoceran Daphnia pulex. Chemosphere 215, 74-81. https://doi.org/10.1016/j.chemosphere.2018.09.176

Martins, A., Guilhermino, L., 2018. Transgenerational effects and recovery of microplastics exposure in model populations of the freshwater cladoceran Daphnia magna Straus. Sci. Total Environ. 631-632, 421-428. https://doi.org/10.1016/j.scitotenv.2018.03.054

Nasser, F., Lynch, I., 2016. Secreted protein eco-corona mediates uptake and impacts of polystyrene nanoparticles on Daphnia magna. J. Proteomics 137, 45-51. https://doi.org/10.1016/j.jprot.2015.09.005

OECD, 2012. Test No. 211: Daphnia magna Reproduction Test. OECD Guidel. Test. Chem. Eff. Biot. Syst. Section 2, 23 p. https://doi.org/10.1787/9789264070127-en

Ogonowski, M., Schür, C., Jarsén, Å., Gorokhova, E., 2016. The effects of natural and anthropogenic microparticles on individual fitness in daphnia magna. PLoS One 11, 120. https://doi.org/10.1371/journal.pone.0155063

544 Ortiz-Perea, N., Gander, R., Abbey, O., Callaghan, A., 2018. The effect of pond dyes on oviposition and survival in wild UK Culex mosquitoes. PLoS One 13, 1-15. https://doi.org/10.1371/journal.pone.0193847

Pablos, M.V., García-Hortigüela, P., Fernández, C., 2015. Acute and chronic toxicity of emerging contaminants, alone or in combination, in Chlorella vulgaris and Daphnia magna. Environ. Sci. Pollut. Res. 22, 5417-5424. https://doi.org/10.1007/s11356-0154119-1

Phuong, N.N., Zalouk-Vergnoux, A., Poirier, L., Kamari, A., Châtel, A., Mouneyrac, C., Lagarde, F., 2016. Is there any consistency between the microplastics found in the field and those used in laboratory experiments? Environ. Pollut. 211, 111-123. https://doi.org/10.1016/j.envpol.2015.12.035 
555 Rist, S., Baun, A., Hartmann, N.B., 2017. Ingestion of micro- and nanoplastics in Daphnia magna - Quantification of body burdens and assessment of feeding rates and reproduction. Environ. Pollut. 228, 398-407. https://doi.org/10.1016/j.envpol.2017.05.048

Rochman, C.M., Brookson, C., Bikker, J., Djuric, N., Earn, A., Bucci, K., Athey, S.,

Sighicelli, M., Pietrelli, L., Lecce, F., Iannilli, V., Falconieri, M., Coscia, L., Di Vito, S.,

Scherer, C., Brennholt, N., Reifferscheid, G., Wagner, M., 2017. Feeding type and development drive the ingestion of microplastics by freshwater invertebrates. Sci. Rep.

Rosenkranz, P.H.R., Chaudhry, Q.A.C., Stone, V.I.S., Ernandes, T.E.F.F., 2009. A Comparision of Nanoparticle and Fine Particle Uptake by Daphnia Magna. Environ. Toxicol. Chem. 28, 2142-2149.

7, 17006. https://doi.org/10.1038/s41598-017-17191-7

Schür, C., Rist, S., Baun, A., Mayer, P., Hartmann, N.B., Wagner, M., 2019. When Fluorescence is not a particle: The tissue translocation of microplastics in Daphnia magna seems an artIfact. Environ. Toxicol. Chem. etc.4436. https://doi.org/10.1002/etc.4436 Nuglio, S., Zampetti, G., 2018. Microplastic pollution in the surface waters of Italian Subalpine Lakes. Environ. Pollut. 236, 645-651. https://doi.org/10.1016/j.envpol.2018.02.008 Smilauer, P., Lepš, J., 2014. Multivariate Analysis of Ecological Data using CANOCO 5. 
SPSS, 2012. No Title SPSS Statistics for Windows.

Su, L., Xue, Y., Li, L., Yang, D., Kolandhasamy, P., Li, D., Shi, H., 2016. Microplastics in Taihu Lake, China. Environ. Pollut. 216, 711-719. https://doi.org/10.1016/j.envpol.2016.06.036

Townroe, S., Callaghan, A., 2015. Morphological and fecundity traits of Culex mosquitoes caught in gravid traps in urban and rural Berkshire, UK. Bull. Entomol. Res. 105, 615620. https://doi.org/10.1017/S000748531500053X

Wagner, M., Lambert, S., 2018. Freshwater Microplastics, The Handbook of Environmental Chemistry. Springer International Publishing, Cham. https://doi.org/10.1007/978-3-319$61615-5$

Wagner, M., Scherer, C., Alvarez-Muñoz, D., Brennholt, N., Bourrain, X., Buchinger, S., Fries, E., Grosbois, C., Klasmeier, J., Marti, T., Rodriguez-Mozaz, S., Urbatzka, R., Vethaak, A., Winther-Nielsen, M., Reifferscheid, G., 2014. Microplastics in freshwater

Wang, W., Gao, H., Jin, S., Li, R., Na, G., 2019. The ecotoxicological effects of microplastics on aquatic food web, from primary producer to human: A review. Ecotoxicol. Environ. Saf. 173, 110-117. https://doi.org/10.1016/J.ECOENV.2019.01.113

601

Wright, S.L., Thompson, R.C., Galloway, T.S., 2013. The physical impacts of microplastics

602 on marine organisms: a review. Environ. Pollut. 178, 483-92.

603 

chronic toxicity in D. magna.

\begin{tabular}{|c|c|c|}
\hline Treatments & $\begin{array}{c}\text { Algae concentrations } \\
(\mu \mathrm{l})\end{array}$ & $\begin{array}{c}\text { Microplastics } \\
\text { concentrations } \\
\left(\mathrm{MPs} \mathrm{ml}^{-1}\right)\end{array}$ \\
\hline Algae (Low) & 100 & 0 \\
\hline Algae (High) & 800 & 0 \\
\hline Algae=MPs (Low) & 100 & 100 \\
\hline Algae=MPs (High) & 800 & 800 \\
\hline Algae>MPs & 800 & 100 \\
\hline MPs> Algae & 100 & 800 \\
\hline
\end{tabular}

607

608

609 Table 2 Classification and number of the species added to each mesocosms.

\begin{tabular}{|c|c|c|c|}
\hline Species & Habitat and feeding & Classification & $\begin{array}{c}\text { Number in each } \\
\text { pond }\end{array}$ \\
\hline Daphnia magna & $\begin{array}{l}\text { Water column } \\
\text { Filter feeder }\end{array}$ & $\begin{array}{l}\text { Class: Branchiopoda } \\
\text { Order: Cladocera } \\
\text { Family: Daphniidae }\end{array}$ & 1000 \\
\hline Culex pipiens & $\begin{array}{l}\text { Water column and } \\
\text { surface } \\
\text { Filter feeder }\end{array}$ & $\begin{array}{l}\text { Class: Insecta } \\
\text { Order: Diptera } \\
\text { Family: Culicidae }\end{array}$ & 15 \\
\hline
\end{tabular}




\begin{tabular}{|l|l|l|c|}
\hline Chironomus & Sediment & Class: Insecta & 30 \\
& Filter feeder & Order: Diptera & \\
\hline Jenkins spire-shell & Water surface and & Class: Gastropoda & \\
Potamopyrgus & sides & Order: Littorinimorpha & 15 \\
antipodarum & Herbivore & Family: Tateidae & \\
\hline Water mite & Water column & Class: Arachnida & \\
Hydrachnidia & Predator & Order: Trombidiformes & \\
& & Family: Hydrachnidiae & \\
\hline
\end{tabular}

610

611

612 